Publ. in: Zwart, Jan-Wouter and Mark de Vries (eds.), Structure Preserved :

Studies in syntax for Jan Koster; Amsterdam [u.a.] : Benjamins, 2010. - S. 31-40. - (Linguistik aktuell ; 164). - ISBN 978-90-272-5547-1

\title{
Wh-drop and recoverability
}

\author{
Josef Bayer \\ University of Konstanz
}

\section{Topic pronoun drop}

One of the remarkable properties of Verb Second (V2) syntax is the fact that the constituent preceding the finite verb - let's for simplicity call it 'SpecCP' - can under certain circumstances be dropped (cf. Ross 1982; Huang 1984; Fries 1988 for German, Ackema \& Neeleman 2007 for Dutch). Pronoun drop is strictly confined to pronouns in SpecCP and can only occur in the root clause. In a context in which, say, Hans is the topic of conversation, a pronoun referring to Hans can be dropped from SpecCP as long as it is recoverable by virtue of linking to structural Case. In German, this restricts topic pronoun drop to nominatives and accusatives. Datives, genitives and pronominal PPs are out (cf. Bayer, Bader \& Meng 2001).

(1) $\{$ Der/ter $\}$ ist im Büro he:Nom is in-the office 'He is in the office.'

(2) $\{$ Den/den $\}$ kenn ich auch him:ACC know I too 'I know him too.'

(3) $\left\{\right.$ Dem $/{ }^{*}$ dem $\}$ schadet das nicht him:DAT harms this not 'This doesn't harm him.'

(4) $\{$ Darüber $/ *$ darüber $\}$ sollst du dich nicht aufregen there-about should you REFL not excite 'You shouldn't get excited about it.'

It is important to notice that the deletion operation is not functionally grounded. The deleted material in (3) and (4) would be fully recoverable: schaden demands dative case, and whenever sich aufregen takes a PP argument, this PP will invariably be headed by the preposition über.

Without pronoun drop it would be hard to explain the example in (5) which I heard someone say. 
(5) Bier kann ich nichts mit anfangen

(German) beer can I nothing with begin

'As for beer, I don't like it.'

Extraction of Bier from PP would violate the ban on P-stranding. According to a well-known analysis that has been suggested in Koster (1978) for subject sentences, (5) receives a natural explanation which is in harmony with the fact that $\mathrm{P}$ can be stranded when its complement is an R-pronoun. According to this analysis, Bier is in a left-dislocated position and is resumed there by an R-pronoun that has been dropped:

(6) $\left[_{\mathrm{CP}} \operatorname{Bier}\left[{ }_{\mathrm{CP}}\right.\right.$ da kann ich nichts ${ }_{\mathrm{PP}}$ da+[mit da $\left.]\right]$ anfangen $\left.]\right]$

Since according to standard assumptions mit assigns dative case, (6) should in connection with (3) raise suspicion. There is evidence, however, that $\mathrm{V}$ and $\mathrm{P}$ do not assign case uniformly. As Bayer, Bader \& Meng (2001) and Bayer \& Bader (2007) argue, (substructures of) functional prepositions are exponents rather than assigners of case. If this is right, the R-pronoun $d a$ does not actually bear dative (or another oblique) case and can therefore be dropped.

The reliability of the rule of topic pronoun drop sets the stage for taking a look at an aspect of this phenomenon which to my knowledge has largely remained unknown so far: wh-drop.

\section{Wh-drop}

Pronoun drop in SpecCP suggests that the pronoun to be dropped refers to a discourse topic. The following data from Bavarian show, however, that even wh can be dropped. Notice that the examples with wh-drop to follow occur only in casual speech and usually come across as unsophisticated or even rude. (PRT is short for 'discourse particle'.)

(7) $\{$ Wos $\}$ is-n do los?

what is-PRT (t)here on

'What's going on $(\mathrm{t})$ here?'

(8) $\{$ Wos $/$ dea-ts-n es do?

what do-2PL-PRT you (t)here

'What are you guys doing $(\mathrm{t})$ here?'

As in the case of pronoun drop, the rule of wh-drop can only affect XPs in SpecCP, never wh-elements in situ as they may occur in multiple questions.

(9) Wer hot -n \{wos/* ${ }^{*}$ g'lesn?

who has-PRT what read

'Who read what?' 
Reversal of the two wh-pronouns as in (10) improves the example significantly although there remains a certain degradation which may be due to an independent mismatch in register.

$$
\begin{aligned}
& \left\{\text { Wos/(?) }{ }^{(?)}\right. \text { hot -n wer g'lesn? } \\
& \text { what has-PRT who read } \\
& \text { 'What did which person read?' }
\end{aligned}
$$

As in the case of topic pronoun drop, the rule of $w h$-drop can only affect $w h$-pronouns with the structural cases nominative and accusative. My research with native speaker informants allows the conclusion that $w$ h-drop can in fact only affect was. Even nominatives and accusatives with a person restrictor ('who') are not allowed. A question like (11) is consistently interpreted with a missing 'what', never with a missing 'who'.

$$
\begin{aligned}
& \text { is-n des? } \\
& \text { is-PRT that } \\
& \text { 'What is that?' } \\
& \text { (not: 'Who is that?') }
\end{aligned}
$$

The same is true for any other semantic restrictions no matter how predictable they may be from the propositional context. On the other hand, was does not need to correspond to an argument. Like various other languages, German allows a non-argumental use of was/what which gives rise to an interpretation that is close to 'why'. Therefore one may refer to it as 'why-like what' (cf. d'Avis, 1996; Bayer \& Obenauer, in press, Munaro \& Obenauer 1999). In Bavarian, why-like was can very naturally be dropped:

$$
\begin{aligned}
& \text { \{Wos/ schau-st-n so deppert!? } \\
& \text { what look-2sG-PRT so stupid } \\
& \text { 'Why are you looking so stupidly!?' }
\end{aligned}
$$

The same is true of the was that occurs in the familiar was für construction. As (13) shows, was can be dropped when it moves alone. (14) shows that was cannot be dropped once it has pied-piped the für-phrase to SpecCP.

$$
\begin{aligned}
& \text { \{Wos/wos\} git-s-n [was fiar-a G'mias]? } \\
& \text { what exists-it-PRT for-a vegetable } \\
& \text { 'What kind of vegetables will we have?' } \\
& \text { (14) }\left[\left\{\mathrm{Wos} /{ }^{*} \mathrm{~s}\right\} \text { fiar-a G'mias }\right] \text { git-s-n? } \\
& \text { what for-a vegetable exists-it-PRT } \\
& \text { 'What kind of vegetables will we have?' }
\end{aligned}
$$

These data show that Bavarian wh-drop is entirely form-driven. (i) As in the case of topic pronoun drop, the process can only target SpecCP and delete the entire material in SpecCP. (ii) As in the case of topic pronoun drop, the process can only affect wh-pronouns with structural case, i.e. with nominative or accusative. These are the 
two cases which are recoverable via the T-system and the $v$-system of the grammar respectively. (iii) Unlike in the case of topic pronoun drop, the dropped wh-pronoun must not be semantically restricted. This leaves only was, which is the maximally underspecified member of the wh-pronouns (cf. Jäger 2000).

\section{The formal license of $w h$-drop}

Given that Bavarian shares with Standard German the option of topic pronoun drop, we may at this point ask how under the drop condition declaratives can be distinguished from $w h$-interrogatives. A plausible answer may be that the interrogative status is recovered by means of rising intonation. Although intonation signals interrogative mood, we notice in all of the Bavarian examples in Section 2 the additional presence of a clitic element $-n$. This element is derived from an older Germanic ancestor that turned into English then, Dutch dan, Old High German thanne, and later modern German dann (temporal 'then') next to denn. (For the history of denn cf. Abraham 1991; Wegener 2002; for recent syntactic approaches that take grammaticalization and variation into account cf. Bayer, in press, Coniglio 2005 and Grosz 2005).

In modern German, denn is a discourse particle which appears in interrogatives and conveys the meaning that the speaker presupposes a common ground with the addressee and links his/her question to this common ground. Thus, denn means roughly "under these circumstances that are know by both speaker and hearer". As a consequence, denn is felt to be odd in out-of-the-blue questions. Denn is only used when the speaker wants to make reference to the presupposed common ground. In this sense, denn is optional.

Notice now the interesting (and certainly interrelated) facts that in Bavarian the clitic $-n$ (i) does not retain the semantics of German denn, and (ii) appears to be obligatory in wh-questions. Both of these properties suggest that the Bavarian version of denn, namely $-n$, has shifted to or is in the process of shifting toward a different category. Since it is obligatorily a clitic that attaches to the finite verb in $\mathrm{C}^{0}$, the reanalysis that $-n$ has undergone may well have resulted in an agreement morpheme that signals agreement with a $w h$-phrase in the associated SpecCP. Whatever the best analysis of the data is, suffixation of $-n$ avoids an ambiguity between topic drop and wh-drop. Notice that the $w h$-drop version of (12), Schau-st-n so deppert, is identified as a question on the basis of the presence of $-n$. Without $-n$, Schau-st so deppert would be a declarative with the second person singular pronoun $d u$ dropped. Interrogative interpretation would be conveyed by intonation.

Nevertheless, ambiguity avoidance alone cannot explain the data. With - $n$ missing, the drop versions of the examples in (7), (8), (11), (12) and (13) are consistently unacceptable as questions. 
(15) * _ is do los?

(Bavarian)

(16) * _ dea-ts es do?

(17) * _ is des ?

(18) * _ schau-st so deppert ?

(19) * _ git-s fiar-a G'mias?

Under the perspective that the clitic $-n$ is a $w h$-agreement marker - perhaps reflecting the unvalued $w h$-feature of $\mathrm{V}_{\text {fin }}$ in $\mathrm{C}^{0}$ - the structure of a $w h$-question is preserved under wh-drop.

(20)

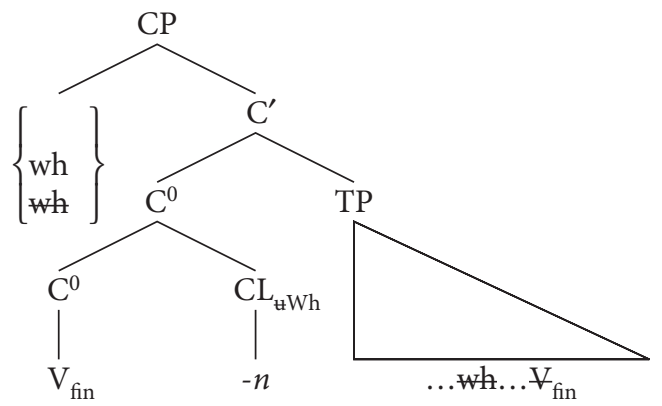

It is unclear whether Standard German allows wh-drop at all. According to my intuitions, examples like _ ist dort passiert? 'What has happened there?' or _ suchst $d u$ dort? 'What are you looking for?' are ungrammatical and could at best be rescued with the insertion of the particle denn: _ ist denn dort passiert? _ suchst du denn dort? This would not be too surprising given that the particle denn - although it is optional in Standard German - is dependent on questions. Wh-questions with a whadjunct could in principle yield ambiguity with a disjunctive question due to the fact that the initial finite verb's position may be taken to be the left edge of the clause. Since we know that only was can be dropped, however, an ambiguity of this sort can hardly ever arise. Cases of potential ambiguity as between (21) and (22) are usually not an issue in German.

(21) kommst du (denn)?

(German)

when come you DENN

'When will you come (after all)?'

(22) Kommst du (denn)?

come you DENN

'Will you come (after all)?'

The reason is that (22) is unavailable with the representation (and semantic interpretation) of (21). An ambiguity could arise, though, in the case of why-like what. According to 
my intuitions, the potential ambiguity seen in (23) bleeds the option of was drop (if it is an option at all).

(23) $\left\{\right.$ Was $/^{\text {** }}$ was $\}$ schreit er denn schon wieder?

what shouts he DENN already again

'Why the hell is he shouting again?'/'Is he shouting again?'

\section{An impression from Dutch}

Cursory research on comparable Dutch data (with the help of Janet Grijzenhout, Henk van Riemsdijk and Jan-Wouter Zwart) reveals - could it be otherwise? - some degree of variation.

Recall that we are again exclusively talking about spoken language. The first thing to notice is that as in German, only the most neutral wh-element can be dropped. In Dutch, this is wat. In spoken language, Dutch seems to allow for wh-drop as in (24).

(24) $\{$ Wat/wat $\}$ zegt-ie?

(Dutch)

what says-he

'What does he say?'

However, echoing (23), wh-drop is less of an option once wh-drop leads to ambiguity with a disjunctive question.

(25) $\left\{\right.$ Wat $/{ }^{2 *}$ at $\}$ is dit hier?

what is this here

'What is this here?'/'Is this here?'

Unambiguous cases of wat-drop as in (26) are okay but there is a tendency to use the adverb/particle nou (literally 'now', but in wh-questions closely corresponding to German denn) as seen in (27) (judgments by Janet Grijzenhout, p.c.).

(26) $\{$ Wat/' wat $\}$ doe je daar? what do you there

'What are you doing there?'

(27) $\{$ Wat/wat $\}$ doe je daar nou?

what do you there nOU

'What then are you doing there?'

The same is true for (28) and (29) (judgments by Jan-Wouter Zwart, p.c.).

(28) $\left\{\right.$ Wat $/{ }^{*}$ wat $\}$ doe jij?

what do you

'What are you doing?' 
(29) $\{$ Wat/wat $\}$ doe jij nou?

what do you Nou

'What then are you doing?'

These data suggest that wh-drop (i) is an option of the grammar of Dutch, (ii) is impossible if it provokes ambiguity with a disjunctive question, and (iii) improves in the presence of a discourse particle like nou which is an indicator of a constituent question.

\section{Comparison with L1-acquisition}

According to Yamakoshi (2002), wh-drop has been observed in child language in Dutch, English, French, German, Spanish and Swedish. Westergaard (2009) reports similar data from child Norwegian. Wh-drop has also been found in American Sign Language (cf. Yamakoshi's report). Westergaard finds significantly more occurrences of $k a$ ('what') drop in comparison with other $w h$-items in Norwegian. According to the sources that Yamakoshi quotes, correspondents of 'how', 'why', 'where', 'who:Nom,'whom:DAT', can also be dropped. In her own data from English, chunks larger as well as smaller than the wh-phrase can be found: Who is hiding in the bucket? next to Which dog is barking? Santelmann $(1995,1997)$ and van Kampen (1997) find in Swedish and Dutch respectively wh-drop also in SpecCP of embedded CPs. Thus, wh-drop in child language is much more liberal than the $w h$-drop observed in adult language. Possibly adult-style wh-drop is a subset of child-style drop, the latter being a reflection of an immature system which does not yet allow the production of all the complexities of $w h$-syntax.

Nevertheless there is an interesting further aspect. Yamakoshi (2002) ran an elicitation task in order to find out about wh-drop in child Japanese. In addition, she explored natural speech data from Japanese children. Both investigations revealed that "wh-drop rarely occurs in child Japanese". She explains this via the difference in operator structure. While in the Western languages under consideration the wh-operator cannot be separated from the actual wh-item, the wh-operator in Japanese is a zero element which is separated from the $w h$-item. The $w h$-item proper is not an operator. This amounts to saying that $w h$-drop is operator drop.

It cannot be overlooked, however, that there might be another strong factor involved, namely the position of the wh-element. The target grammar shows that both wh-drop and topic pronoun drop occur only in SpecCP of the root clause, i.e. in the functionally defined position $\left[\mathrm{CP}-\mathrm{V}_{\text {fin }} \ldots\right]$, and that the option of dropping is subject to rigid conditions of recoverability. It is controversial whether lower whphrases occur in a comparable position in wh-in-situ languages. Yamakoshi's findings suggest that children who acquire a V2 language or a language with partial V2 (alias 'T2', cf. Koster 2003) have an early sensitivity to the functional architecture of the adult 
grammar. As we have seen, wh-drop is a phenomenon that is well in the range of the adult target grammar.

\section{Conclusion}

Although there is far too little information about wh-drop so far, the data that have been compiled here suggest that $w h$-drop is closely related to the phenomenon of topic pronoun drop as familiar from the syntax of German and Dutch. Both processes target SpecCP. Both processes are subject to rigid requirements of recoverability. The case of the deleted element can only be one of the two structural cases. In the case of $w h$-drop the constraints on dropping are more severe. First, the $w h$-item to be dropped can only be the wh-item par excellence, namely 'what'. Secondly, there must in all likelihood be extra features in the clause which guarantee interpretation of a $w h$-question once the primary morphosyntactic exponent of the question, the wh-item itself, is phonetically absent. In Bavarian this feature is provided by $-n$, an element that derives from the discourse particle denn and seems to have turned into a marker of wh-agreement in this dialect. In colloquial German and Dutch, question-sensitive particles appear to be more or less obligatorily involved in wh-drop. It is a matter of current research to determine how discourse particles contribute to the determination of the illocutionary force of an utterance. Although much work will be needed to close the various gaps that my preliminary investigation leaves, the impression is that wh-drop is under close control of structure preservation.

\section{Acknowledgments}

Thanks to Ellen Brandner, Janet Grijzenhout, Liliane Haegeman, Henk van Riemsdijk and Jan-Wouter Zwart for discussion and Iris Bräuning and Marco Veser for editorial help. Any responsibilities are on my side.

\section{References}

Abraham, Werner. 1991. The grammaticalization of German modal particles. In Elisabeth Traugott \& Bernd Heine (eds.), Approaches to grammaticalization II [Typological Studies in Language 19: 2], 331-380. Amsterdam: John Benjamins.

Ackema, Peter \& Neeleman, Ad. 2007. Restricted pro drop in early modern Dutch. Journal of Comparative Germanic Linguistics 10: 81-107.

Bayer, Josef, Bader, Markus \& Meng, Michael. 2001. Morphological underspecification meets oblique Case: Syntactic and processing effects in German. Lingua 111: 465-514. 
Bayer, Josef \& Bader, Markus. 2007. On the syntax of prepositional phrases. In Andreas Späth (ed.), Interfaces and interface conditions, 157-180. Berlin: Walter de Gruyter.

Bayer, Josef. In press. From modal particle to interrogative marker: A study of German denn. In Anna Cardinaletti, Giuliana Giusti, Nicola Munaro \& Cecilia Poletto (eds.), Functional heads. Oxford: OUP.

Bayer, Josef \& Obenauer, Hans-Georg. In press. Discourse particles, clause structure, and question types. The Linguistic Review.

Coniglio, Marco. 2005. Deutsche Modalpartikeln: Eine syntaktische Analyse. MA thesis, University of Venice.

d'Avis, Franz-Josef. 1996. On 'empty' questions. In Uli Lutz \& Gereon Müller (eds.), Papers on Wh-Scope Marking [Arbeitspapiere des Sonderforschungsbereichs 340: Sprachtheoretische Grundlagen für die Computerlinguistik. Bericht Nr. 76], 331-360. Stuttgart: Universität Stuttgart/Universität Tübingen /IBM Deutschland.

Fries, Norbert. 1988. Über das Null-Topik im Deutschen. Sprache und Pragmatik 3: 19-49.

Grosz, Patrick. 2005. Dn in Viennese German: The syntax of a clitic version of the discourse particle denn. MA thesis, University of Vienna.

Huang, C.T. James. 1984. On the distribution and reference of empty pronouns. Linguistic Inquiry 15: 531-574.

Jäger, Andreas. 2000. Unterspezifikation am Beispiel des Pronomens was: Zur Grammatik eines w-Elements. MA thesis, Friedrich Schiller University Jena.

van Kampen, Jacqueline. 1997. First steps in Wh-movement. Ph.D. dissertation, Utrecht University.

Koster, Jan. 1978. Why subject sentences don't exist. In Samuel J. Keyser (ed.), Recent transformational studies in European languages, 53-64. Cambridge MA: The MIT Press.

Koster, Jan. 2003. All languages are tense-second. In Jan Koster \& Henk van Riemsdijk (eds.), Germania et alia: A linguistic webschrift for Hans den Besten. <http://www.let.rug.nl/koster/ DenBesten/contents.htm>.

Munaro, Nicola \& Obenauer, Hans-Georg. 1999. On underspecified wh-elements in pseudointerrogatives. University of Venice Working Papers in Linguistics 9: 181-253.

Ross, John Robert. 1982. Pronoun deleting processes in German. Paper presented at the Meeting of the Linguistic Society of America, San Diego.

Santelmann, Lynn. 1995. The acquisition of Verb Second grammar in child Swedish. Ph.D. dissertation, Cornell University.

Santelmannn, Lynn. 1997. Wh-less questions in early Swedish: An argument for continuity in language development. Cornell Working Papers in Linguistics 15: 217-253.

Wegener, Heide. 2002. The evolution of the German modal particle denn. In Ilse Wischer \& Gabriele Diewald (eds.), New reflections on grammaticalization [Typological Studies in Language 49], 379-393. Amsterdam: John Benjamins.

Westergaard, Marit. 2009. Microvariation as diachrony: A view from acquisition. Journal of Comparative Germanic Linguistics 12: 49-79.

Yamakoshi, Kyoko. 2002. Wh-drop in child languages and adult ASL. Proceedings of Console IX, 217-231. 
